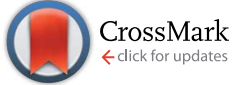

Cite this: RSC Adv., 2016, 6, 20926

\title{
Interconnected PVDF-CTFE hydrophobic membranes for MD desalination: effect of PEGs on phase inversion process $\dagger$
}

\author{
Libing Zheng, ${ }^{\text {ab }}$ Jun Wang, ${ }^{\text {ab }}$ Yuansong Wei, ${ }^{\text {ab }}$ Yong Zhang, ${ }^{\text {ab }}$ Kun Li $^{\text {ab }}$ \\ and Zhenjun $\mathrm{Wu}^{\mathrm{c}}$
}

In this work, poly(vinylidene fluoride-co-chlorotrifluoroethylene) (PVDF-CTFE) was used for hydrophobic membrane preparation by the non-solvent induced phase inversion (NIPS) technique. The effects of poly(ethylene glycol) (PEG) molecular weight and dosage were investigated in terms of the membrane morphology, contact angle, surface free energy, and membrane pore structure for both surface pores and overall pores. All membranes possessed a typical liquid-liquid demixing asymmetric structure and the contact angles were higher than $85^{\circ}$. Furthermore, increasing the PEG molecular weight and dosage significantly altered the membrane pore structure and surface roughness as a result of the variation of the phase inversion process. The solid-liquid demixing was responsible for the variation of membrane morphology, pore structure, hydrophobicity, and DCMD performance as PEGs with higher molecular weight or dosage were added. The PVDF-CTFE membranes were suitable for MD application owing to their high hydrophobicity, small pore size with narrow pore distribution, high DCMD performance, especially the interconnected pore structure. The membrane containing 5 wt\% PEG-400 was evidenced to be the optimal one for the MD process, mainly according to the high interconnected pore structure which provide more passages for vapour transfer. The permeate flux was $17.98 \mathrm{~kg}\left(\mathrm{~m}^{-2} \mathrm{~h}^{-1}\right)$ with a conductivity as low as $7 \mu \mathrm{cm}^{-1}$ at the temperature difference of $30{ }^{\circ} \mathrm{C}$. In addition, an excellent performance sustainability was observed including a relatively steady permeate flux and conductivity during the $360 \mathrm{~h}$ continuous DCMD operation.

Received 30th December 2015

Accepted 22nd January 2016

DOI: $10.1039 / c 5 r a 28081 \mathrm{~h}$

www.rsc.org/advances driving force in MD is the vapour pressure difference induced by the temperature difference across the membrane, which only allows for the transportation of vapour molecules. As a result, high salt rejection can be envisioned even under low operation pressure and temperature, presenting tremendous advantages over conventional thermal- or membrane-based desalination processes. $^{\mathbf{8 , 9}}$

The preparation of an appropriate membrane for MD presents a great challenge for both academia and industry. The membranes need to be hydrophobic and possess appropriate pore structure and morphology. In addition, excellent mechanical and chemical stability is also required to maintain a stable performance. ${ }^{10}$ PVDF is currently considered to be the most suitable polymer due to its excellent hydrophobicity and processability compared to other hydrophilic membrane materials such as polyethylene (PE), polypropylene (PP), and polytetrafluoroethylene (PTFE). ${ }^{7,11,12}$ However, hydrophobic PVDF membranes still facing many technical limitations impeding its further application, which mainly related to its low mechanical strength, hydrophobicity and permeate flux. In this regard, efforts have been dedicated to the search of alternative materials for membrane fabrication and the improvement in membrane preparation process, as well as the development of composite membrane and nano-composite membrane. ${ }^{13-16}$ The 
PVDF-based copolymer, which possesses higher hydrophobicity due to its high fluorine content, attracted considerable attention as an alternative choice for hydrophobic membrane preparation. $^{12}$ Poly(vinylidene fluoride-co-tetrafluoroethylene) (PVDF-TFE), poly(vinylidene fluoride-co-trifluoroethylene) (PVDF-TrFE), poly(vinylidene fluoride-co-hexafluoropropylene) (PVDF-HFP) and few other PVDF-based graft copolymers have been used in hydrophobic membrane preparation. ${ }^{17}$

PVDF-CTFE is another commercial fluoropolymer which possess excellent mechanical strength, high hydrophobicity, and good chemical and thermal stability due to the presence of C-F bond..$^{12,18}$ And it can be easily grafted via atom transfer radical polymerization (ATRP) owing to the CTFE segment. Thus, it has been employed for membrane preparation through either NIPS ${ }^{19-24}$ or electro-spinning processes. ${ }^{25,26}$ However, to the best knowledge of the authors, the natural hydrophobicity of PVDF-CTFE was largely overlooked, and a systematic study of PVDF-CTFE hydrophobic membrane preparation is desperately needed. In this regard, it is of great interests to study the use of PVDF-CTFE copolymer for hydrophobic membrane preparation and its potential application in MD. It was confirmed that PVDF-CTFE copolymer has several competitive advantages over other PVDF homopolymers and as well as great potentials for hydrophobic membrane fabrication in a previous study. ${ }^{27}$

NIPS is commonly applied for polymeric membrane preparation, in which the phase inversion process was easily influenced by many factors and led to membrane with various morphology and pore structure. Additives has been widely used to fine-tune the membrane morphology and permeability based on this knowledge. It could not only alters the solvation power of the solvent, but also affects the phase inversion process both thermodynamically and kinetically. ${ }^{28}$ PEG is one of the most commonly used additive, which has been studied in both hydrophilic and hydrophobic membrane preparation. ${ }^{29-32}$ It was reported that when using PEG as additive, its molecular weight and dosage showed great but diversified impact on membrane properties. $^{33-35}$ As the same additive may even show entirely different effects on different multi-component polymer solution systems, its effect on PVDF-CTFE hydrophobic membrane preparation should carefully concerned as PEGs was used as additives.

In this study, PVDF-CTFE copolymer was used for hydrophobic membrane preparation. The objective was to tune the membranes by the addition of PEGs with different molecular weight and dosage. Membranes morphology, surface and overall pore structure, porosity, and hydrophobicity were studied to demonstrate the influence of PEG additives form the perspective of variation in phase inversion process. The permeability of resultant membranes was investigated by DCMD test, and a $360 \mathrm{~h}$ continuous DCMD test was also carried out to investigate the membrane sustainability.

\section{Material and methods}

\subsection{Materials}

Commercial PVDF-CTFE copolymer powder (Solef®, 32008) was purchased from Solvay (Belgium) and was dried at $50{ }^{\circ} \mathrm{C}$ for 24 hours before use. DMAc (>99\%) was obtained from Shanghai Jingwei Chemical Co., Ltd. (Shanghai, China). PEGs with molecular weights ranging from 200 to $2000 \mathrm{Da}$ were supplied by Tianjin Guangfu Research Institute of Fine Chemical Engineering (Tianjin, China). Porefil@ liquid used as the wetting fluid was purchased by Porometer (Eke, Belgian). Ethanol (GR grade, 99.9\%), $\mathrm{NaCl}$ (GR grade, 99.5\%), glycerol (AR, 99\%), and diiodomethane (CP) were all purchased from Beijing Chemical Works (Beijing, China). Deionized water was used as coagulant for membrane preparation.

\subsection{Membrane preparation}

Pre-dried PVDF-CTFE copolymer powder, DMAc and predesigned amounts of PEGs with different molecular weights were mixed in a sealed flask and stirred at $30{ }^{\circ} \mathrm{C}$ for $24 \mathrm{~h}$ to obtain a homogeneous polymer solution (detailed was shown in Table 1). For all casting solutions, the polymer concentration was $12 \mathrm{wt} \%$. The homogeneous polymer solution was then allowed for degassing in a vacuum oven at $30^{\circ} \mathrm{C}$ for $24 \mathrm{~h}$.

Flat sheet PVDF-CTFE hydrophobic membranes were prepared by the dry-wet phase inversion method (also known as NIPS). Prior to membrane casting a piece of hydrophilic PET nonwoven fabric, which function as the supporting layer to prevent membrane shrinking and enhance membrane mechanical strength, was attached on a spotless flat glass plate. The casting solution was subsequently cast uniformly on the surface of the supporting layer by a casting knife with a gap of $0.25 \mathrm{~mm}$. After exposing in air for $15 \mathrm{~s}$, the film was immersed into a deionized water bath at $25{ }^{\circ} \mathrm{C}$. The prepared nascent membranes were then removed from the coagulation bath and washed with running water to remove the residual additives and solvent. Finally, the wet membranes were air dried at room temperature and stored for subsequent measurement and testing.

\subsection{Membrane morphology}

The membrane surface and cross-section morphologies were observed using a HITACHI SU8020 field emission scanning electron microscope (FE-SEM) (Hitachi, Japan). The FE-SEM was operated under standard high-vacuum conditions at $3.00 \mathrm{kV}$. The samples for cross-section observation were firstly frozen in liquid nitrogen for cryogenic fracturing to maintain the pore structure. All the samples were sputtered with gold nanoparticles under vacuum with a HITACHI E1010 Ion Sputtering device (Hitachi, Japan) prior to SEM observation.

\subsection{Membrane surface morphology and pore structure}

As topography would affect the brightness in SEM images, it can be used to indicate the state of membrane surface. ${ }^{36,37}$ Membrane coupons with a size of $12.7 \times 8.8 \mu \mathrm{m}$ was scanned using SEM and the $10000 \times$ magnified images were obtained and be further analysed using the image-pro-plus 6.0 software. The pore size, surface porosity, pore roundness, and the SEM roughness index ${ }^{38}$ were calculated to understand the 
Table 1 Compositions of the polymer solutions for membrane casting

\begin{tabular}{lrrrrrrrrr}
\hline Membrane code & M1 & M2 & M3 & M4 & M5 & M6 & M7 & M8 & M9 \\
\hline Molecular weight of PEG & 200 & 400 & 600 & 1000 & 2000 & - & 400 & 400 & 400 \\
PEG concentration (wt\%) & 5 & 5 & 5 & 5 & 5 & 0 & 1 & 3 & 7 \\
DMAc concentration (wt\%) & 83 & 83 & 83 & 83 & 83 & 88 & 87 & 85 & 81 \\
\end{tabular}

surface pore structure, and the detailed methods were shown in the ESI. $\dagger$ The grayscale histograms and three dimension (3-D) morphology was obtained by image J software as described in previous works, ${ }^{\mathbf{3 9 , 4 0}}$ and the method was shown in the ESI. $\dagger$

\subsection{Porosity, pore size and pore size distribution}

The overall porosity of the membrane was defined as the volume proportion of the pores over the total volume of the membrane, gravimetric method was applied to determine the porosity. The membrane sample was tore apart off from the nonwoven fabric supporting layer and immersed in ethanol solution and ultrapure water for each $24 \mathrm{~h}$ to fill the membrane pores with ethanol and then replace it with ultrapure water. Finally, the wet membranes and dried membrane were weighed, and the membrane porosity $(\varepsilon)$ was calculated by the following equation:

$$
\varepsilon=\frac{\left(M_{\mathrm{w}}-M_{\mathrm{d}}\right) / \rho_{\mathrm{w}}}{\left(M_{\mathrm{w}}-M_{\mathrm{d}}\right) / \rho_{\mathrm{w}}+M_{\mathrm{d}} / \rho_{\mathrm{p}}}
$$

where $M_{\mathrm{w}}$ is the weight of the wet membrane, $M_{\mathrm{d}}$ is the weight of the dry membrane, $\rho_{\mathrm{w}}$ and $\rho_{\mathrm{p}}$ are the density of water and membrane, respectively.

Apart from the porosity measurement, the bubble point, pore size and pore size distribution of the flat sheet membranes were also investigated by gas-liquid displacement method using a Capillary Flow Porometer Porolux 1000 (Porometer, Belgium) to study the effects of PEGs on the permeation properties as described in other work. ${ }^{\mathbf{4 1}}$ The gas flux percentage was plotted against the pore size to represent the percentage of the corresponding pores.

\subsection{Membrane hydrophobicity}

The contact angles of membranes with 3 liquids with different polarity (i.e., deionized water, glycerol, and diiodomethane) were measured to evaluate the membranes hydrophobicity using an OCA 15EC Video-Based Contact Angle Meter (Data Physics, Germany). Five different positions of each membrane sample were measured and the average value was reported with the standard deviation.

The membrane surface free energy was calculated by adopt the Owens method ${ }^{42}$ as follows:

$$
\gamma_{\mathrm{L}}(1+\cos \theta)=2\left(\gamma_{\mathrm{S}}^{\mathrm{d}} \gamma_{\mathrm{L}}^{\mathrm{d}}\right)^{1 / 2}+2\left(\gamma_{\mathrm{S}}^{\mathrm{p}} \gamma_{\mathrm{L}}^{\mathrm{p}}\right)^{1 / 2}
$$

where, $\gamma_{S}, \gamma_{L}, \gamma_{S}^{\mathrm{d}}, \gamma_{\mathrm{S}}^{\mathrm{p}}, \gamma_{\mathrm{L}}^{\mathrm{d}}, \gamma_{\mathrm{L}}^{\mathrm{p}}$ are the surface free energy of the solid and liquid, dispersion force term and polar force term of the solid, dispersion force term and polar force term of the liquid, respectively. The surface free energy of these liquid and their dispersion force term and polar force term are presented in Table S1.†

\subsection{DCMD set-up and membrane permeability}

The desalination performance of the PVDF-CTFE membranes was evaluated using a laboratory-scale DCMD set-up (shown in Fig. 1A). Sodium chloride aqueous solution $\left(35 \mathrm{~g} \mathrm{~L}^{-1}\right)$ and distillated water were used as the hot feed and cold permeate, respectively. The upper layer of membranes was contact with feed side and the supporting layer was contact with permeate side. Both side circulated with constant flow rate at $65 \mathrm{~L} \mathrm{~h}^{-1}$ and $50 \mathrm{~L} \mathrm{~h}^{-1}$ by magnetic pumps. The flat-sheet membrane module was consisted of two self-designed polymethyl methacrylate (PMMA) plate as shown in Fig. 1B. The flat-sheet membrane with an effective area of $5.218 \times 10^{-3} \mathrm{~m}^{2}$ was tightly clamped
A

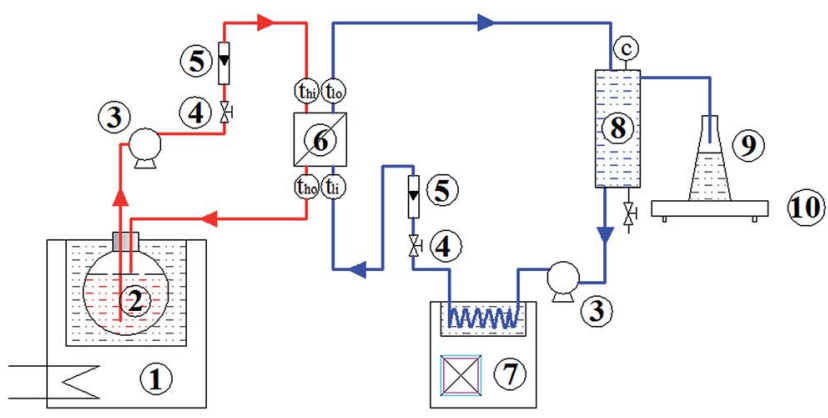

B

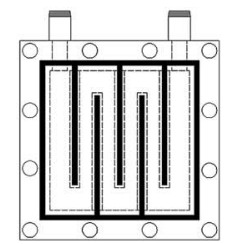

Fig. 1 (A) Schematic diagram of the DCMD set-up: (1) super thermostat, (2) feed solution, (3) magnetic pump, (4) valve, (5) rotameter, (6) flatsheet membrane module, (7) cryostat, (8) distillate collector, (9) conical flask, (10) balance, t. Thermometer, c. Conductivity meter; (B) design diagram of the flat-sheet membrane module. 
between the plates. The temperatures of both sides were kept at $55{ }^{\circ} \mathrm{C}$ and $25{ }^{\circ} \mathrm{C}$. The concentration of sodium chloride in the distillate was monitored with an electric conductivity monitor. The permeate flux $(J)$ was calculated using the following equation:

$$
J=\frac{m}{A t}
$$

where $J$ is the permeate flux $\left[\mathrm{kg}\left(\mathrm{m}^{-2} \mathrm{~h}^{-1}\right)\right], m$ is the quantity of permeate $(\mathrm{kg}), A$ is the membrane effective area $\left(\mathrm{m}^{2}\right)$ and $t$ represents the sampling time (h). The salt rejection coefficient $R$ was calculated according to the following equation:

$$
R=\frac{C_{\mathrm{f}}-C_{\mathrm{p}}}{C_{\mathrm{f}}}
$$

where $C_{\mathrm{f}}$ and $C_{\mathrm{p}}$ are the salt concentrations of the feed and permeate, respectively.

The sustainability of the hydrophobic membrane in DCMD process was also examined in this work using the same MD setup with a $360 \mathrm{~h}$ continuous operation. The test was conducted under the same operation condition as in the permeate test, and the permeate flux and conductivity were recorded at set intervals.

\section{Results and discussion}

\subsection{Membrane morphology by SEM}

The effects of molecular weight and dosage of PEG on the membrane micro-structure were systematically evaluated by FESEM images observation, as shown in Fig. 2 and 3.

Fig. 2A and B clearly showed that the shape of the surface pores changed from circular to irregular and the interconnectivity increased along with the molecular weight of PEGs. Such an observation can be attributed to the phase inversion process because the formation of the top surface owing to the demixing of the casting solution by means of nucleation and growth of the polymer-rich phase. ${ }^{43}$ Increased the molecular weight of PEGs, the casting solution became thermodynamically unstable and the viscosity became higher according to the
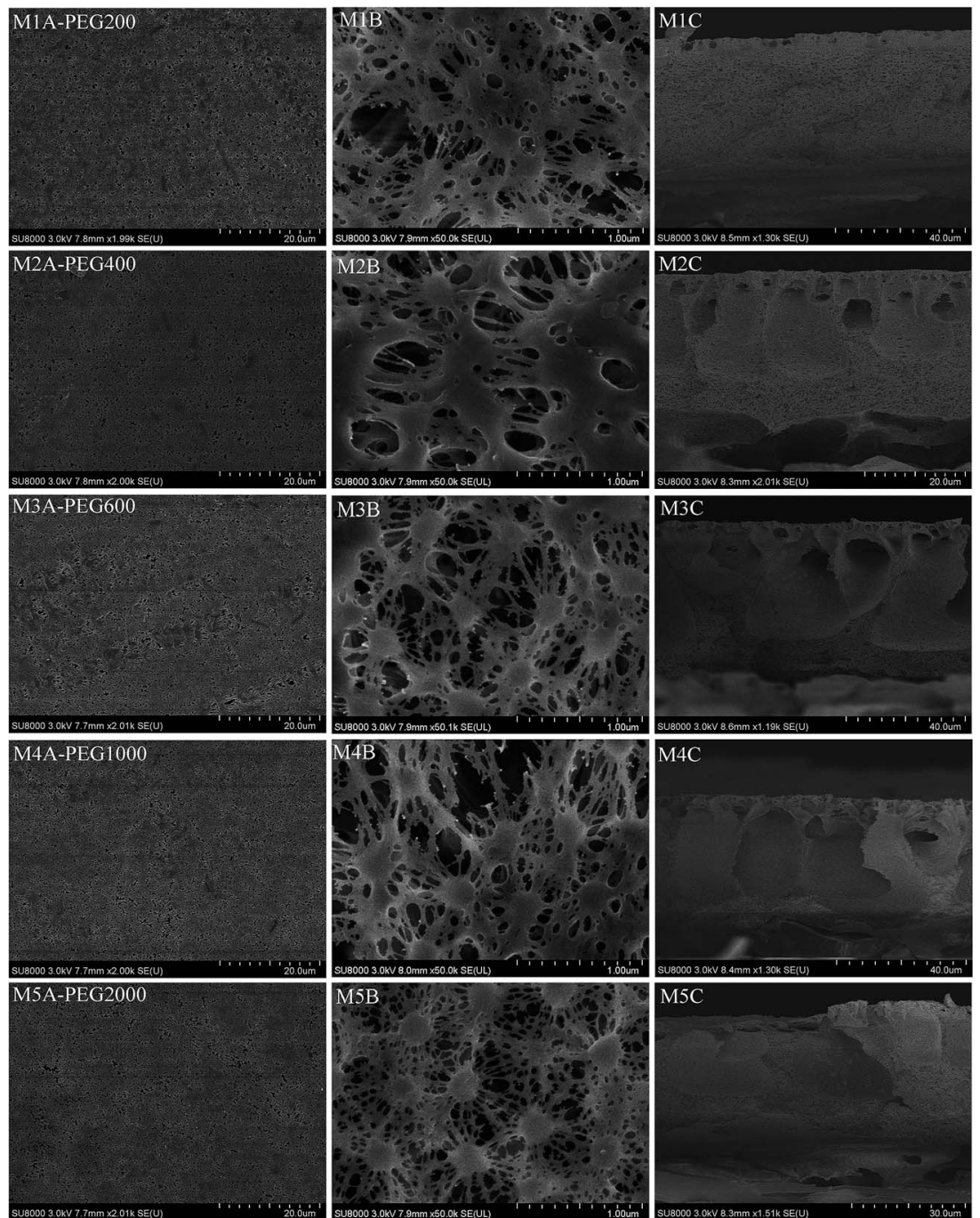

Fig. 2 FE-SEM images of PVDF-CTFE membranes by PEG additives with different molecular weights: (M1A-M5A) membrane surface; (M1B-M5B) $50000 \times$ magnified image of membrane surface; (M1C-M5C) membrane cross-section. 


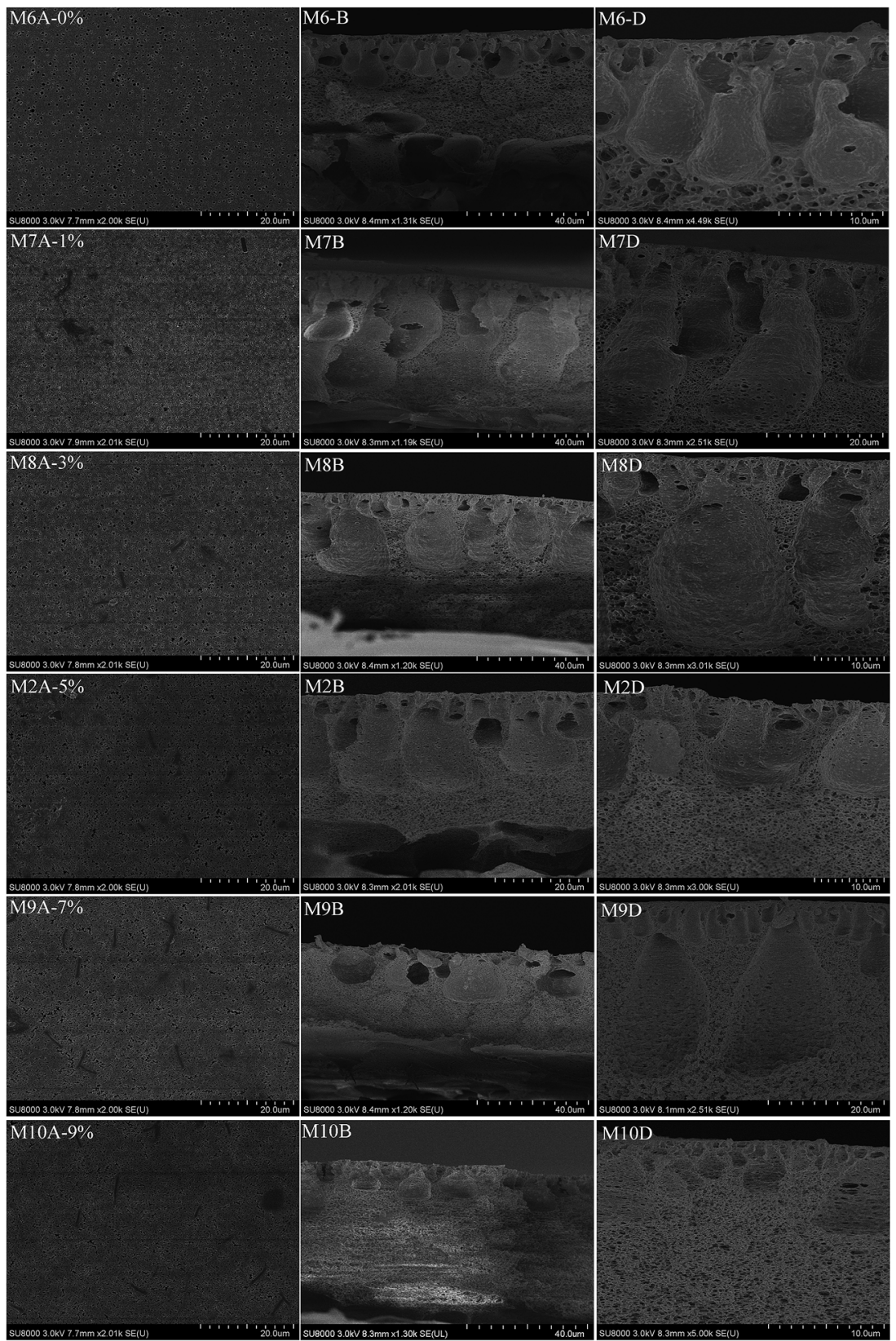

Fig. 3 FE-SEM images of the PVDF-CTFE membranes by PEG-400 with different dosage: (M6A-M10A) membrane surface; (M6B-M10B) membrane cross-section; (M6D-M10D) macro-voids in the membrane cross-section.

entanglement of macromolecular among polymer, solvent, and additive. As a result, the solution with lower mobility in the initial stage of immersion benefited the solid-liquid demixing (S-L) for the lower exchange rate of solvent and non-solvent. Which in turn encouraged the aggregation of the crystallites on membrane surface. ${ }^{44}$ On the contrary, the use of low molecular weight PEG encouraged the fast exchange of solvent and non-solvent, thus leading to an instantaneous liquid-liquid demixing ( $\mathrm{L}-\mathrm{L})$. That is, polymer crystallization process presented more influence as the molecular weight increased due to the decreasing phase inversion rate. The large circular pores found on the surface of membranes prepared using the lower molecular weight PEG was resulted from the L-L demixing during phase inversion, which was responsible for the formation of the enclosed and poorly interconnected pores. As PEGs with higher molecular weight were used, spheroidal crystallites was formed by S-L demixing (polymer crystallization) as shown Fig. 2B. As a result, irregular pores with higher interconnectivity was formed in membrane surface.

The cross-section of the PVDF-CTFE membranes containing PEGs additives with different molecular weight were showed in Fig. 2C. All membranes displayed a typical asymmetric structure consisting of a dense top layer, a number of macrovoids, and sponge-like sub-layer, which was typically formed during the L-L demixing process. Furthermore, it was observed that the size of the macrovoids expanded along with the increasing PEG 
molecular weight, which was in good agreement with previous studies. ${ }^{32,33}$ So it is safe to say that L-L demixing dominated the phase inversion process for all the casting solution. However, the role of S-L demixing was increasingly important as the molecular weight increased due to the lower phase inversion rate as discussed for membrane surface. So the polymer crystals showed up in membrane cross-section and the pore interconnectivity was also significantly improved when using the PEGs with higher molecular weight. The phenomenon discovered in this work was in line with the previous work, ${ }^{34}$ they also demonstrated that the $\mathrm{L}-\mathrm{L}$ demixing rate decreased and the S-L demixing started to take place when high molecular weight PEGs were used during the phase inversion process.

The effect of PEG dosage on the membrane morphology was also investigated by FESEM as shown in Fig. 3. The pores on membrane surface became irregular and interconnected when increasing the dosage of PEG, and it was clearly that the number and size of the macrovoids in cross-section were firstly increased and then suppressed when increase the dosage of PEG. Fig. 3D further demonstrated that walls of pores including the macrovoids and the sponge-like layer were converted from imporous to open structure when increasing the PEG dosage, and the crystallites appeared when preparing the membranes with high PEG dosage. The morphology variation can also be attributed to the different phase inversion process induced by
PEG. As the PEG dosage was lower than $3 \mathrm{wt} \%$, the phase inversion rate increased as the dosage increased because the PEG which acted as additive would decreased the stability of casting solution and promote the exchange rate of solvent and non-solvent. As a result, the membrane showed typical asymmetric structure in cross-section by instantaneous phase inversion. While as the dosage was higher than $5 \mathrm{wt} \%$, the thermodynamic effect showed greater influence which significantly increased the viscosity of casting solution. So the phase inversion rate decreased due to the lower exchange rate of solvent ant non-solvent. The delayed phase inversion process was benefit the S-L demixing, so the pores became irregular and the interconnectivity increased when further increase the PEG dosage as M2, M9, and M10 shown. Meanwhile, the phase inversion process induced by PEG with different dosage was also responsible for the two-stage promotion and suppression of the macro-voids in cross-section, as the instantaneous phase inversion was benefit the grow of macro-voids and vice versa.

\subsection{Membrane surface roughness and pore structure}

Fig. 4 showed the 3-D graphs and grayscale distribution of the membranes with different PEG dosage, the original $10000 \times$ magnified SEM micrographs was shown in Fig. S3. $\dagger$ It can be found that the membrane roughness increased as the PEG dosage increased, this can be attributed to the crystals formed
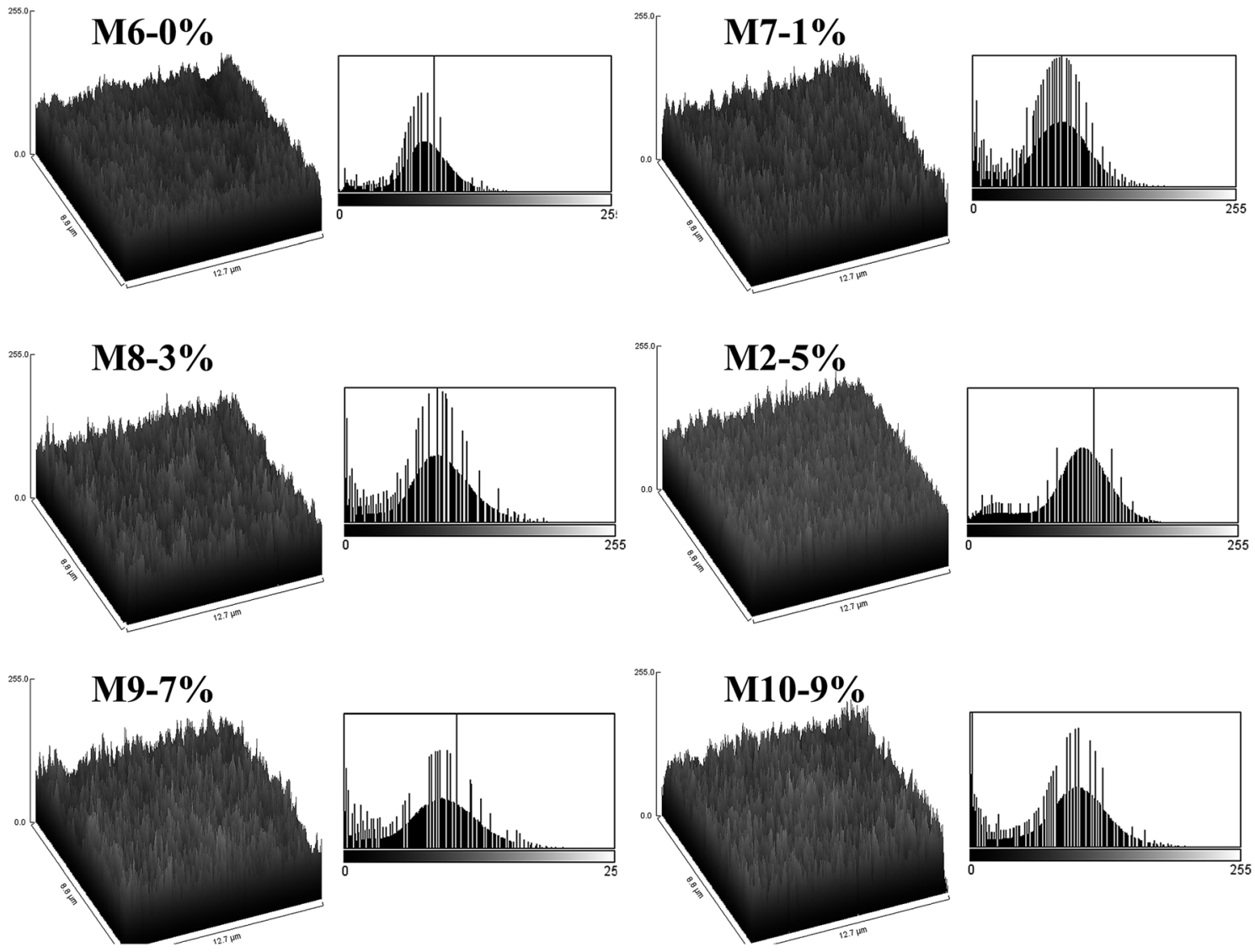

Fig. 4 3-D graphs and histograms of the grayscale value of each pixels of SEM micrographs of membrane prepared by PEGs with different molecular weight. 
by the S-L demixing when more PEG was added. The grayscale histograms showed that the range of grayscale distribution became broader along with the PEG dosage, which also evidenced the increase of membrane roughness. The effect of PEG molecular weight on membrane surface 3-D morphology was also investigated as shown in Fig. S1, $\uparrow$ with the original SEM image showed in Fig. S2.† The morphology and grayscale distribution showed slightly variation when the molecular weight was lower than $600 \mathrm{Da}$, while both exhibited significantly increase when molecular weight was higher than 1000 Da (M4 and M5). This observation can be ascribed to the solution stability and viscosity due to the addition of higher molecular weight PEG additives.

Table 2 showed the pore structure and roughness of the membrane surface, which was also obtained based on the SEM micrographs by image-pro-plus 6.0. It is clear that the surface porosity increased first but then decreased as the molecular weight was higher than 1000 Da when increase the molecular weight, however it increased along with the molecular weight for PEG dosage. The SEM roughness index showed good correlation with the surface 3-D morphology, i.e. increased along with the PEG molecular weight and dosage. The roundness of the surface pore was bigger when PEG with higher molecular weight or dosage was employed as compared to membrane with lower molecular weight or dosage, which means the pores shape altered bigger. However, the pore size showed no clear correlation with the PEG molecular weight or dosage which can be confirmed by Fig. S1 and S2. $\dagger$ The pore structure variation can also be explained by the phase inversion process during the membrane formation. As discussed in Section 3.1, the S-L demixing imposed significant influence with the increased of PEG molecular weight and dosage, and the crystallization was beneficial for the formation of interconnected pore structure and rougher surface. The interconnected pore structure was benefit the surface porosity, roundness, and roughness. However, as the PEG additives with ultra-high molecular weight were used (i.e. higher than 1000 $\mathrm{Da}$ ), the polymer-rich phase dominated the surface composition. As a result, the porosity decreased as the membrane samples M4 and M5 showed. For surface pore size, it was influenced both by the porosity and the pore structure, these two opposite effects worked together which lead to the final pore size as can be found in Table 2 and related SEM graphs. In a word, the surface pore structure was totally affected by the phase inversion process which was influenced by PEGs with different molecular weight and dosage.

\subsection{Membrane hydrophobicity}

The hydrophobicity was represented by the contact angle and surface free energy in this work, and the results were showed in Table 3 .

It was clearly evidenced that the hydrophobicity decreased when increasing the dosage of PEG, however the decreasing trend was reduced when more PEG was added. Correspondingly, the hydrophobicity firstly decreased as the molecular weight was lower than $600 \mathrm{Da}$ and then increased when further increasing the molecular weight. On one hand, the addition of PEG was reported to decrease the hydrophobicity of membrane. ${ }^{45,46}$ On the other hand, the crystallites formed on the membrane surface due to the high dosage or molecular weight increased the membrane surface roughness, and thus leading to a higher hydrophobicity. ${ }^{47,48}$ These two contrary effect induced by PEGs with different molecular weight or dosage worked together to the hydrophobic of the resultant membranes. As the molecular weight or dosage was relatively lower, the first factor played more important role which result in the decrease of hydrophobicity. While the later factor presents greater influence as the molecular weight or dosage increased, so the decreasing rate of hydrophobicity decreased or the increasing trend was observed when PEG-1000 or PEG-2000 was used due to its strong impact on membrane roughness. It was in agreement with the previous work when PEG was used for PVDF-HFP hydrophobic membrane preparation. ${ }^{49}$ Such a variation was mainly believed to be caused by the variation in surface roughness due to the polymer crystallisation.

\subsection{Porosity, pore size and pore distribution}

The effect of PEG molecular weight and dosage on membrane overall porosity, pore size and pore size distribution were investigated and the results were showed in Table 4 and Fig. 5. It

Table 2 Pore structure and roughness of the membranes surface calculated by image-pro-plus 6.0

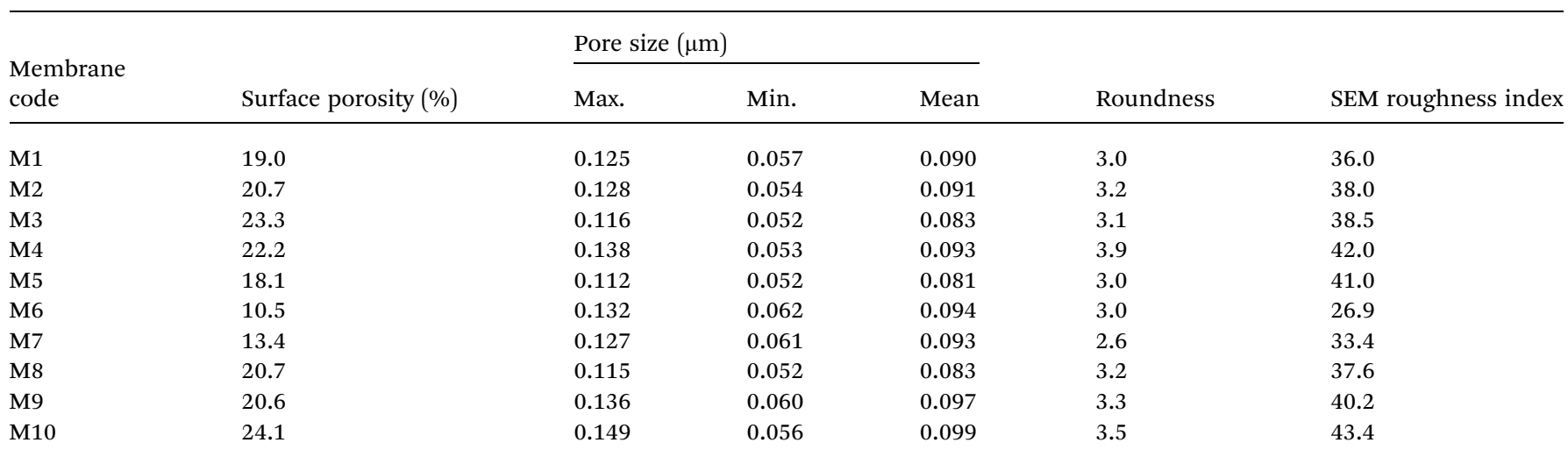


Table 3 CA with different regents and the calculated surface free energy of the flat-sheet membranes

\begin{tabular}{|c|c|c|c|c|}
\hline $\begin{array}{l}\text { Membrane } \\
\text { code }\end{array}$ & $\mathrm{CA}_{\text {water }}\left({ }^{\circ}\right)$ & $\mathrm{CA}_{\text {glycerol }}\left({ }^{\circ}\right)$ & $\mathrm{CA}_{\text {diiodomethane }}\left({ }^{\circ}\right)$ & $\gamma\left(\times 10^{-5} \mathrm{~N} \mathrm{~cm}^{-1}\right)$ \\
\hline M1 & $90.48 \pm 3.57$ & $78.92 \pm 3.24$ & $58.24 \pm 1.28$ & $33.68 \pm 1.06$ \\
\hline M2 & $87.30 \pm 4.08$ & $76.83 \pm 1.62$ & $55.32 \pm 1.75$ & $36.10 \pm 1.64$ \\
\hline M3 & $81.53 \pm 3.67$ & $70.38 \pm 2.51$ & $52.03 \pm 0.94$ & $40.52 \pm 3.91$ \\
\hline M4 & $83.11 \pm 3.10$ & $71.52 \pm 3.27$ & $54.23 \pm 2.42$ & $38.98 \pm 3.71$ \\
\hline M5 & $84.32 \pm 4.04$ & $71.98 \pm 1.37$ & $54.80 \pm 0.89$ & $38.29 \pm 3.32$ \\
\hline M6 & $92.58 \pm 3.18$ & $80.26 \pm 2.16$ & $59.53 \pm 1.37$ & $32.34 \pm 0.70$ \\
\hline M7 & $90.28 \pm 3.69$ & $78.13 \pm 2.45$ & $58.73 \pm 0.77$ & $33.74 \pm 1.29$ \\
\hline M8 & $87.32 \pm 3.14$ & $77.03 \pm 1.38$ & $56.75 \pm 0.98$ & $35.55 \pm 1.95$ \\
\hline M9 & $86.22 \pm 3.56$ & $75.92 \pm 2.71$ & $55.26 \pm 1.61$ & $36.65 \pm 2.11$ \\
\hline M10 & $86.36 \pm 1.59$ & $76.38 \pm 0.86$ & $54.76 \pm 0.62$ & $36.83 \pm 2.12$ \\
\hline
\end{tabular}

Table 4 The overall porosity and pore size measured by Porometer Porolux 1000

\begin{tabular}{|c|c|c|c|c|}
\hline $\begin{array}{l}\text { Membrane } \\
\text { code }\end{array}$ & Overall porosity (\%) & Max. & Min. & Mean \\
\hline M2 & $65.5 \pm 0.79$ & $0.234 \pm 0.030$ & $0.105 \pm 0.005$ & $0.132 \pm 0.015$ \\
\hline M3 & $71.7 \pm 0.67$ & $0.262 \pm 0.065$ & $0.120 \pm 0.015$ & $0.146 \pm 0.017$ \\
\hline M4 & $72.5 \pm 0.74$ & $0.217 \pm 0.051$ & $0.092 \pm 0.012$ & $0.137 \pm 0.035$ \\
\hline M7 & $62.2 \pm 1.01$ & $0.162 \pm 0.068$ & $0.092 \pm 0.024$ & $0.113 \pm 0.016$ \\
\hline M8 & $67.1 \pm 0.52$ & $0.178 \pm 0.066$ & $0.081 \pm 0.002$ & $0.130 \pm 0.032$ \\
\hline M9 & $65.0 \pm 1.39$ & $0.295 \pm 0.087$ & $0.115 \pm 0.032$ & $0.150 \pm 0.047$ \\
\hline M10 & $65.4 \pm 0.66$ & $0.486 \pm 0.125$ & $0.121 \pm 0.056$ & $0.174 \pm 0.043$ \\
\hline
\end{tabular}

A

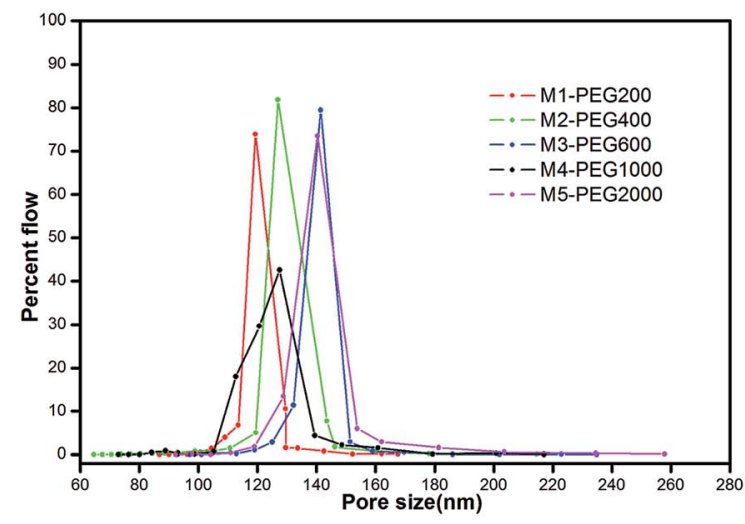

B

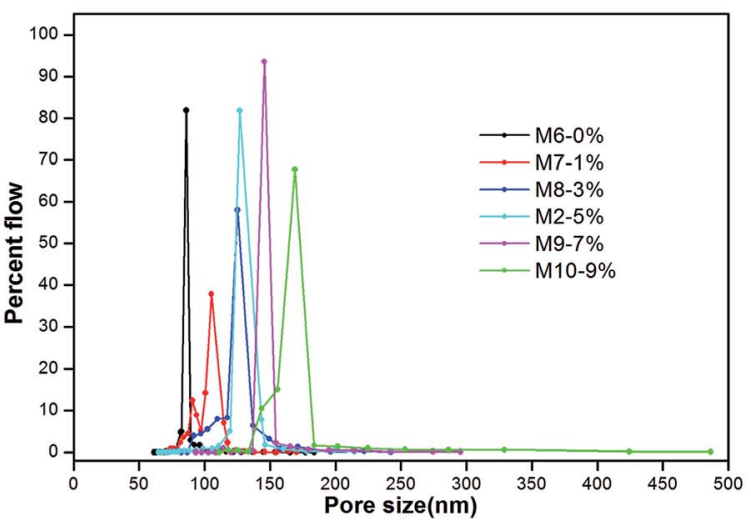

Fig. 5 Pore size distribution of the PVDF-CTFE membranes using PEG additives with (A) different molecular weight, and (B) different dosage.

was observed in Table 4 that the membrane porosity was greatly improved when increasing the PEG molecular weight from 200 to $400 \mathrm{Da}$, while further increase in molecular weight only possessed slightly improvement. The membrane pore size also presents a similar trend. Fig. 5A showed that M2 and M4 presented the narrowest and broadest pore distribution, respectively. In terms of the effect of PEG dosage, it was noteworthy that the membrane prepared without PEG presented a slightly higher porosity than the membrane M7 due to the lowest relative polymer concentration as can be seen in Table 4 . The overall porosity slightly increased as the dosage was lower than $5 \mathrm{wt} \%$ and decreased as $7 \mathrm{wt} \%$ PEG was added, then reincreased when more PEG was added. Overall, the PEG dosage showed slightly influence on membrane overall porosity although the macrovoids of membrane by less than $5 \mathrm{wt} \%$ dosage was larger. The higher pore interconnectivity of the membrane with higher PEG dosage was believed to offset the absence of macrovoids, and the higher porosity of M9 further 
verified this viewpoint. However, the pore size increased straight along with the PEG dosage and membranes with different dosage present narrow pore distribution as can be found in Fig. 5B.

In a word, the addition of PEG influenced the membrane formation both thermodynamically and kinetically, which may result in both pore-forming and pore-inhibiting effect. The synergetic effect of these two opposite factors was responsible for the variation of membrane pore structure. Based on the results presented in Table 4 and Fig. 5 , it can be inferred that the PVDF-CTFE membrane containing 5 wt\% PEG-400 (M2) might offer excellent separation performance in MD desalination due to its moderate pore size and narrow pore distribution, as well as the interconnected pore structure pore structure as shown in Fig. 3.

\subsection{Membrane desalination performance}

The permeability and rejection of resultant membranes in DCMD desalination was showed in Fig. 6 in terms of the permeate flux, permeate conductivity, and the salt rejection. The salt rejection was nearly $100 \%$ when 5 wt $\%$ PEG with different molecular weights were used as shown in Fig. 6A. Whilst the permeate flux was greatly affected by the molecular weight of the additives, with M2 showing the highest water flux. It was in line with the morphological structure of the M2 membrane, which contained well-interconnected pore structure, moderate pore size and narrow pore size distribution.

The PEG dosage also possessed significant impact on the membrane performance as shown in Fig. 6B. Interestingly, it was found that the permeate flux of M7 was slightly lower than M6, which was prepared without PEG addition. That can be explained by the higher hydrophobicity and porosity of membrane M6. However, the permeate flux was increased along with the PEG dosage, and the increasing rate was more pronounced in the lower dosage range (from 1 to $5 \mathrm{wt} \%$ ). It also should be noted that the membranes M9 and M10 were not suitable for the MD desalination process as a substantial decrease in salt rejection was observed due to the highest pore size as shown in Fig. 5.
PVDF-CTFE membrane with 5 wt\% PEG-400 was therefore considered as the candidate of choice for the MD process in the current study due to its interconnected pore structure, small pore size and narrow pore distribution, as well as the excellent desalination performance. The long-term operation performance of membrane M2 was then examined to demonstrate the sustainability performance of this membrane. A $360 \mathrm{~h}$ continuous desalination experiment was carried out, and the separation results were shown in Fig. 7. The conductivity decreased quickly in the first $10 \mathrm{~h}$, indicating a high permeate flux with low permeate conductivity had been offered. In the meantime, the permeate flux was maintained at approximately $18 \mathrm{~kg} \mathrm{~m} \mathrm{~m}^{-2}$ $\mathrm{h}^{-1}$ during the first $50 \mathrm{~h}$. Furthermore, the permeate flux remained almost constant at $18 \mathrm{~kg} \mathrm{~m}^{-2} \mathrm{~h}^{-1}$ during the entire period, with a marginal decline of less than $8 \%$. Meanwhile, the permeate conductivity maintained lower than $13 \mu \mathrm{S} \mathrm{cm} \mathrm{cm}^{-1}$, although a slight increase trend was found $50 \mathrm{~h}$ later. The results shown in Fig. 7 indicating that the PVDF-CTFE membranes prepared in this study exhibited stable long-term performance, and had great potential in MD process.

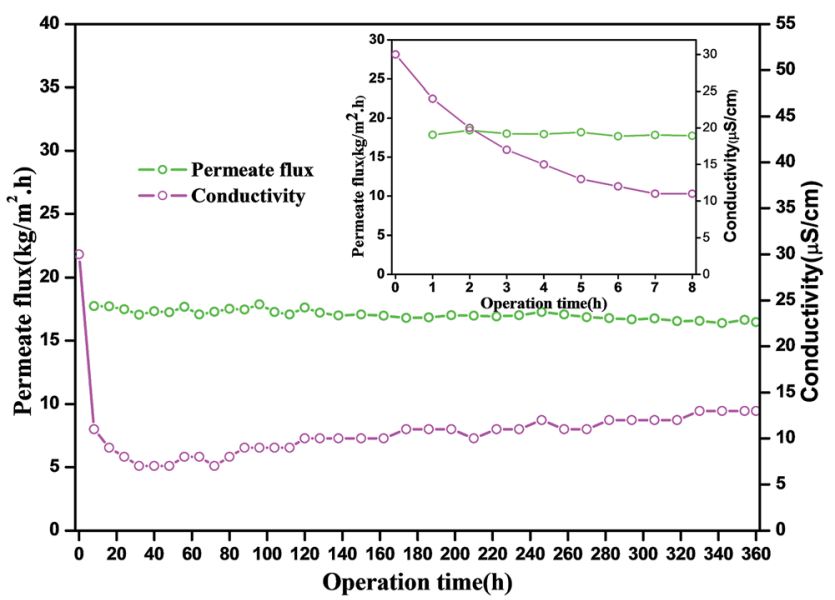

Fig. 7 Long-term desalination operation performance of the PVDFCTFE membrane (feed solution and temperature: $35 \mathrm{~g} \mathrm{~L}^{-1} \mathrm{NaCl}$ solution, $55^{\circ} \mathrm{C}$; permeate temperature: $25^{\circ} \mathrm{C}$ ).
A

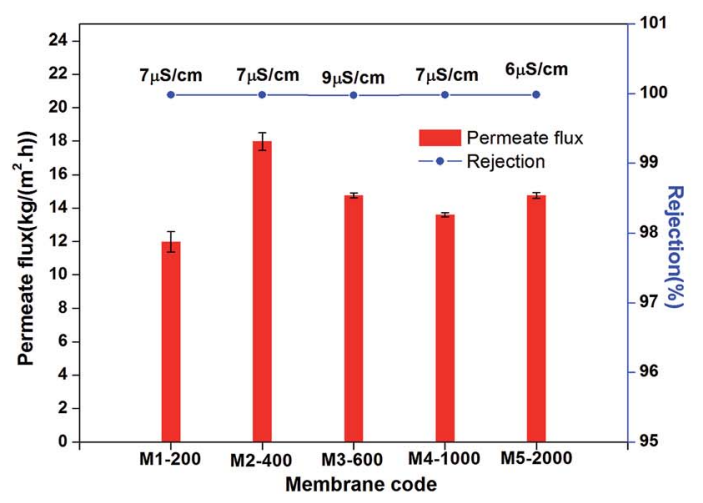

B

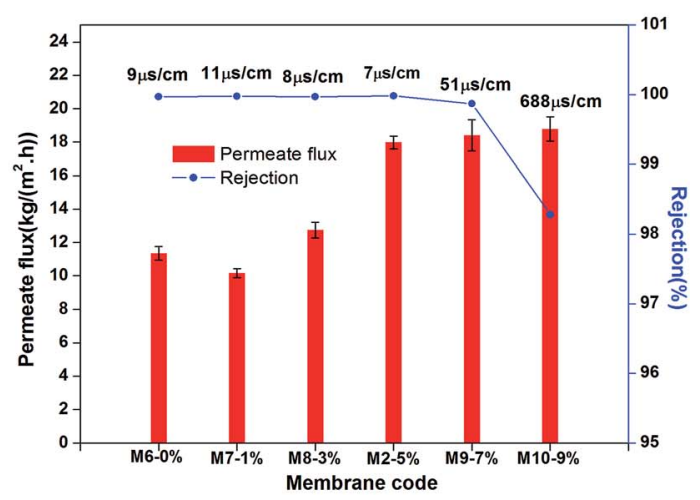

Fig. 6 MD desalination performance of the PVDF-CTFE membranes using PEG additives with (A) different molecular weight, and (B) different dosage (feed solution and temperature: $35 \mathrm{~g} \mathrm{~L}^{-1} \mathrm{NaCl}$ solution, $55^{\circ} \mathrm{C}$; permeate temperature: $25^{\circ} \mathrm{C}$ ). 
Table 5 Comparison with other reported hydrophobic flat-sheet membranes by different polymer material in DCMD process

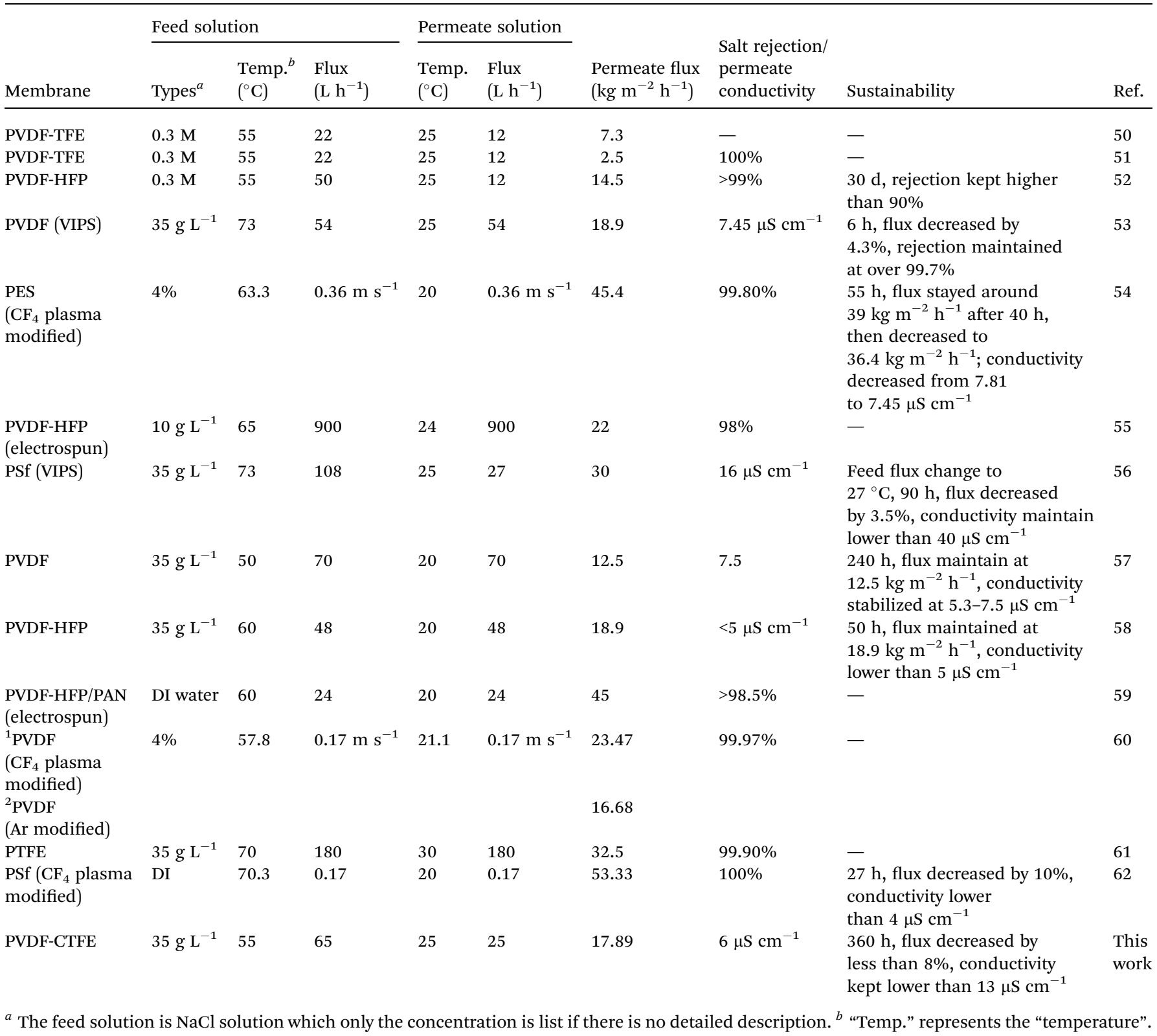

\subsection{Comparison with other hydrophobic membranes for MD}

The DCMD performance of the membrane developed in this study was compared with other hydrophobic polymer membranes reported in recent years and the results were compiled in Table $5 .^{50-62}$ It can be found that the PVDF-CTFE membrane prepared in this work presented competitive advantages in permeate flux over other reported hydrophobic membranes at a temperature difference of $30{ }^{\circ} \mathrm{C}$, which was 138.5\% higher than PVDF membrane ${ }^{53}$ and $23.4 \%$ higher than PVDF-HFP membrane. ${ }^{48}$ While for salt rejection or permeate conductivity, the conductivity was $6 \mu \mathrm{S} \mathrm{cm} \mathrm{cm}^{-1}$ (i.e., 99.98\%) in this work, the PVDF-CTFE membrane also can be competitive as can be found in the Table 5 . As to membrane sustainability, the membranes prepared by PVDF-CTFE in the current study showed excellent performance as the permeate flux and the conductivity kept stable during the 360 h continuous operation, which also showed competitive advantage to the comparison membranes. These results clearly suggested that the PVDFCTFE copolymer was an excellent substitute for the preparation of hydrophobic membrane, because of the interconnected pore structure by crystallization, narrow pore distribution, and higher hydrophobicity. With careful tuning of the membrane properties using appropriate additives, these membranes showed great potentials in the MD applications.

\section{Conclusions}

In this study, hydrophobic PVDF-CTFE membranes were prepared for MD desalination application. Effects of molecular 
weight and dosage of PEG additives were systematic studied in terms of membrane morphology, pore structure, hydrophobicity, and separation performance. It was revealed that the molecular weight and dosage of PEG have similar impact on membranes surface morphology and pore structure. The pores became irregular and interconnected while the surface porosity increased by the increasing molecular weight and dosage of PEG. In addition, the cross-section pore interconnectivity was also greatly improved with the increasing molecular weight and dosage of PEG. The effect of PEGs on phase inversion was responsible for the variation of membrane morphology and pore structure. The S-L demixing possessed more important effect on membrane porosity, pore size, and pore interconnectivity with the increase of the molecular weight or dosage of PEGs. Increasing the molecular weight or dosage of PEG encouraged the formation of crystallites, which resulted in a rougher membrane surface, and increased the membrane hydrophobicity. It also worth to mention that all membranes displayed a water contact angles higher than $81.5^{\circ}$, which was suit for MD application.

The optimal membrane structure was found on the membrane with $5 \mathrm{wt} \%$ PEG-400, which presents small pore size and narrow pore distribution, high hydrophobicity, especially the high interconnected pore structure which provide more passages for vapour transfer. A flux of $17.89 \mathrm{~kg} \mathrm{~m}^{-2} \mathrm{~h}^{-1}$ with a rejection higher than $99.99 \%$ was achieved for this membrane. Long-term desalination test revealed that the PVDFCTFE membrane with $5 \mathrm{wt} \%$ PEG-400 delivered nearly constant permeation flux and salt rejection after $360 \mathrm{~h}$ continuous DCMD operation, indicating excellent performance sustainability of this membrane. This contribution clearly demonstrated that the PEGs with different molecular weight and dosage has significant influence on the resultant membranes mainly by the influence on phase inversion process, and the PVDF-CTFE hydrophobic membrane prepared in this work has great potential in DCMD desalination application due to the morphology, pore structure, properties variation induced by S-L demixing during membrane formation.

\section{Acknowledgements}

The authors was gratefully appreciate for the support by the National Natural Science Foundation of China (Grant No. 51378491, No. 51578533, and No. 21307149).

\section{References}

1 A. Subramani and J. G. Jacangelo, Water Res., 2015, 75, 164187.

2 L. F. Greenlee, D. F. Lawler, B. D. Freeman, B. Marrot and P. Moulin, Water Res., 2009, 43, 2317-2348.

3 M. Elimelech and W. A. Phillip, Science, 2011, 333, 712-717. $4 \mathrm{~J}$. E. Miller, Review of water resources and desalination technologies, Sandia national labs unlimited release report SAND-2003-0800, 2003.

5 S. Burn, M. Hoang, D. Zarzo, F. Olewniak, E. Campos, B. Bolto and O. Barron, Desalination, 2015, 364, 2-16.
6 E. Curcio and E. Drioli, Sep. Purif. Rev., 2005, 34, 35-86.

7 A. Alkhudhiri, N. Darwish and N. Hilal, Desalination, 2012, 287, 2-18.

8 P. Wang and T. S. Chung, J. Membr. Sci., 2015, 474, 39-56.

9 A. Alklaibi and N. Lior, Desalination, 2005, 171, 111-131.

10 M. Khayet, Adv. Colloid Interface Sci., 2011, 164, 56-88.

11 F. Liu, N. A. Hashim, Y. Liu, M. M. Abed and K. Li, J. Membr. Sci., 2011, 375, 1-27.

12 B. Ameduri, Chem. Rev., 2009, 109, 6632-6686.

13 Y. Yang, D. Rana, T. Matsuura, S. Zheng and C. Q. Lan, RSC Adv., 2014, 4, 38711-38717.

14 M. Qtaishat, D. Rana, T. Matsuura and M. Khayet, AIChE J., 2009, 55, 3145-3151.

15 Z. Chen, D. Rana, T. Matsuura, Y. Yang and C. Q. Lan, Sep. Purif. Technol., 2014, 133, 303-312.

16 J. E. Efome, D. Rana, T. Matsuura and C. Q. Lan, Water Res., 2016, 89, 39-49.

17 Z. Cui, E. Drioli and Y. M. Lee, Prog. Polym. Sci., 2014, 39, 164-198.

18 F. Boschet and B. Ameduri, Chem. Rev., 2013, 114, 927-980.

19 J. H. Koh, Y. W. Kim, J. T. Park and J. H. Kim, J. Polym. Sci., Part B: Polym. Phys., 2008, 46, 702-709.

20 J. H. Koh, J. A. Seo, J. T. Park and J. H. Kim, J. Colloid Interface Sci., 2009, 338, 486-490.

21 Y. W. Kim, J. K. Choi, J. T. Park and J. H. Kim, J. Membr. Sci., 2008, 313, 315-322.

22 J. H. Koh, Y. W. Kim, J. T. Park, B. R. Min and J. H. Kim, Polym. Adv. Technol., 2008, 19, 1643-1648.

23 F. Liu, M. R. M. Abed and K. Li, Chem. Eng. Sci., 2011, 66, 2735.

24 Y. W. Kim, J. T. Park, J. H. Koh, D. K. Roh and J. H. Kim, J. Membr. Sci., 2008, 325, 319-325.

25 H. Lee, M. Alcoutlabi, O. Toprakci, G. Xu, J. V. Watson and X. Zhang, J. Solid State Electrochem., 2014, 18, 2451-2458.

26 H. Lee, M. Alcoutlabi, J. V. Watson and X. Zhang, J. Appl. Polym. Sci., 2013, 129, 1939-1951.

27 J. Wang, L. Zheng, Z. Wu, Y. Zhang and X. Zhang, J. Membr. Sci., 2016, 497, 183-193.

28 Q. Z. Zheng, P. Wang and Y. N. Yang, J. Membr. Sci., 2006, 279, 230-237.

29 M. Khayet, C. Cojocaru and M. García-Payo, J. Membr. Sci., 2010, 351, 234-245.

30 G. Arthanareeswaran, D. Mohan and M. Raajenthiren, J. Membr. Sci., 2010, 350, 130-138.

31 Y. H. Zhao, B. K. Zhu, X. T. Ma and Y. Y. Xu, J. Membr. Sci., 2007, 290, 222-229.

32 S. Wongchitphimon, R. Wang, R. Jiraratananon, L. Shi and C. H. Loh, J. Membr. Sci., 2011, 369, 329-338.

33 J. H. Kim and K. H. Lee, J. Membr. Sci., 1998, 138, 153-163.

34 B. Chakrabarty, A. Ghoshal and M. Purkait, J. Membr. Sci., 2008, 309, 209-221.

35 A. Idris, N. M. Zain and M. Noordin, Desalination, 2007, 207, 324-339.

36 G. De Silveira, P. Forsberg, T. Conners and S. Banerjee, Surf. Anal. Pap., 1995, 47-71.

37 G. Chinga-Carrasco, M. Lenes, P. O. Johnsen and E. L. Hult, Micron, 2009, 40, 761-768. 
38 S. Banerjee, R. Yang, C. E. Courchene and T. E. Conners, Ind. Eng. Chem. Res., 2009, 48, 4322-4325.

39 Z. Chen, D. Rana, T. Matsuura, D. Meng and C. Q. Lan, Chem. Eng. J., 2015, 276, 174-184.

$40 \mathrm{Z}$. Chen, Study on Structure and Vacuum Membrane Distillation Performance of PVDF Composite Membranes: Influence of Molecular Weight and Blending, University of Ottawa, 2014.

41 C. Agarwal, A. K. Pandey, S. Das, M. K. Sharma, D. Pattyn, P. Ares and A. Goswami, J. Membr. Sci., 2012, 415-416, 608-615.

42 D. K. Owens and R. Wendt, Estimation of the surface free energy of polymers, J. Appl. Polym. Sci., 1969, 13, 1741-1747.

43 K. Kimmerle and H. Strathmann, Desalination, 1990, 79, 283-302.

44 R. Boom, I. Wienk, T. Van den Boomgaard and C. Smolders, J. Membr. Sci., 1992, 73, 277-292.

45 S. Wongchitphimon, R. Wang, R. Jiraratananon, L. Shi and C. H. Loh, J. Membr. Sci., 2011, 369, 329-338.

46 Y. H. Zhao, B. K. Zhu, X. T. Ma and Y. Y. Xu, J. Membr. Sci., 2007, 290, 222-229.

47 M. Rafat, D. De, K. Khulbe, T. Nguyen and T. Matsuura, J. Appl. Polym. Sci., 2006, 101, 4386-4400.

48 Q. Li, Z. L. Xu and M. Liu, Polym. Adv. Technol., 2011, 22, 520531.

49 Q. F. Alsalhy, K. T. Rashid, S. S. Ibrahim, A. H. Ghanim, B. Van der Bruggen, P. Luis and M. Zablouk, J. Appl. Polym. Sci., 2013, 129, 3304-3313.
50 C. Feng, B. Shi, G. Li and Y. Wu, J. Membr. Sci., 2004, 237, 1524.

51 C. Feng, B. Shi, G. Li and Y. Wu, Sep. Purif. Technol., 2004, 39, 221-228.

52 C. Feng, R. Wang, B. Shi, G. Li and Y. Wu, J. Membr. Sci., 2006, 277, 55-64.

53 H. Fan and Y. Peng, Chem. Eng. Sci., 2012, 79, 94-102.

54 X. Wei, B. Zhao, X. M. Li, Z. Wang, B. Q. He, T. He and B. Jiang, J. Membr. Sci., 2012, 407, 164-175.

55 B. S. Lalia, E. Guillen-Burrieza, H. A. Arafat and R. Hashaikeh, J. Membr. Sci., 2013, 428, 104-115.

56 Y. Peng, Y. Dong, H. Fan, P. Chen, Z. Li and Q. Jiang, Desalination, 2013, 316, 53-66.

57 D. Hou, H. Fan, Q. Jiang, J. Wang and X. Zhang, Sep. Purif. Technol., 2014, 135, 211-222.

58 Y. Liao, R. Wang and A. G. Fane, Environ. Sci. Technol., 2014, 48, 6335-6341.

59 L. D. Tijing, Y. C. Woo, M. A. H. Johir, J. S. Choi and H. K. Shon, Chem. Eng. J., 2014, 256, 155-159.

60 C. Yang, X. M. Li, J. Gilron, D. F. Kong, Y. Yin, Y. Oren, C. Linder and T. He, J. Membr. Sci., 2014, 456, 155-161.

61 A. K. Fard, Y. M. Manawi, T. Rhadfi, K. A. Mahmoud, M. Khraisheh and F. Benyahia, Desalination, 2015, 360, 97107.

62 M. Tian, Y. Yin, C. Yang, B. Zhao, J. Song, J. Liu, X.-M. Li and T. He, Desalination, 2015, 369, 105-114. 